\title{
Effet du traitement de la paille de brousse à l'urée et de la complémentation sur la consommation de paille, le poids vif et la note d'état corporel des ovins sahéliens en saison sèche
}

\author{
M Cissé 1, A Fall 3, AM Sow 2, P Gongnet 3, A Korrea 1 \\ 1/nstitut Sénégalais de Recherches Agricoles (ISRA) BP 2057 Dakar; ${ }^{2}$ Société Agro-alimentaire (SOCA), BP \\ 8403 Dakar; $^{3}$ Ecole Inter-Etats des Sciences et Médecine Vétérinaires (EISMV), BP 5077 Dakar, Sénégal
}

La paille de brousse, pâturage naturel herbacé de saison sèche, a une faible valeur nutritive, notamment en azote (Guérin et al, 1988, Rev Elev Méd Pays Trop, 41, 427-440). En zone sahélienne, elle représente la presque totalité des ressources alimentaires disponibles pour les ruminants d'octobre à juin, et ne permet pas de couvrir leurs besoins nutritionnels. L'effet du traitement de la paille de brousse à l'urée et de l'apport de concentré (50\% tourteau d'arachide $+50 \%$ graines de coton) sur les performances zootechniques des ovins en fin de saison sèche a été étudié.

Quarante béliers de race peul-peul, agés de 2 ans et de poids vif moyen de $27,7 \pm 3,2$ $\mathrm{kg}$, ont été répartis en 4 lots équilibrés sur la base du poids vif et de la note d'état corporel. La ration était constituée de paille de brousse non traitée pour le lot 1 , de paille traitée à l'urée pour le lot 2, de paille non traitée plus $500 \mathrm{~g}$ de concentré pour le lot 3 , et de paille traitée plus $500 \mathrm{~g}$ de concentré pour le lot 4 . La composition chimique de la paille de brousse récoltée au mois de novembre était la suivante (en $\mathrm{g} / \mathrm{kg} \mathrm{MS}$ ) : MAT $=54, \mathrm{NDF}=710$, ADF $=$ 445 et $A D L=102$. Une partie de la paille a été traitée en fosse à la dose de $4 \%$ d'urée pendant 14 jours. Sa teneur en MAT, NDF, ADF et ADL était respectivement de 109, 644, 504 et $91 \mathrm{~g} / \mathrm{kg} \mathrm{MS}$. La paille a été offerte ad libitum dans les 4 lots. L'essai a débuté en février 1995 et a duré 105 jours, dont 15 jours d'adaptation aux rations. Les quantités ingérées ont été mesurées quotidiennement.

Le traitement à l'urée a augmenté de $22 \%$ l'ingestion de matière sèche de paille $(p<0,01)$, amélioré la digestibilité de la matière sèche (dMS, mesurée en cage de digestibilité) de 10 points $(43,2$ vs $53,2 \%$ ) (Chenost et Dulphy, 1987, Les Fourrages secs, INRA, 199-230) et permis une augmentation du gain moyen quotidien (GMQ) de $28,4 \mathrm{~g} \quad(\mathrm{p}<0,05)$. L'interaction avec l'apport de concentré a été positive et significative $(p<0,01)$. L'effet du traitement n'a pas été significatif sur la variation de note d'état corporel. L'apport de concentré a augmenté la note d'état corporel de 0,6 point $(p<0,01)$. La paille traitée à l'urée peut donc constituer un bon aliment d'entretien en saison sèche, non seulement pour maintenir le poids vif et l'état des animaux, mais aussi, pour améliorer les performances de reproduction et réduire les mortalités (adultes et jeunes). La paille traitée pourrait constituer également un bon aliment de base pour l'embouche paysanne. En effet, elle peut se subsituer aux matières premières habituellement utilisées (fanes d'arachides) qui sont aujourd'hui difficilement accessibles, suite aux spéculations importantes dont elles font l'objet.

\begin{tabular}{|c|c|c|c|c|c|c|c|c|}
\hline & Lot 1 & Lot 2 & Lot 3 & Lot 4 & & & & \\
\hline $\begin{array}{c}n= \\
\text { Ration de base }{ }^{1}\end{array}$ & $\begin{array}{c}8 \\
\text { PNT }\end{array}$ & $\begin{array}{l}11 \\
\mathrm{PT}\end{array}$ & $\begin{array}{l}11 \\
\text { PNT }\end{array}$ & $\begin{array}{l}11 \\
\text { PT }\end{array}$ & $\mathrm{T}$ & C & $\mathrm{T}^{*} \mathrm{C}$ & ETR \\
\hline $\begin{array}{l}\text { Concentré }(\mathrm{g} / \mathrm{j} / \mathrm{tête}) \\
\text { Paille ingérée }\end{array}$ & 0 & 0 & 500 & 500 & & & & \\
\hline (kgMS/j/tête) & 0,7 & 0,9 & 0,6 & 0,8 & * & ** & ** & 0,4 \\
\hline $\begin{array}{l}\text { Poids initial }(\mathrm{kg}) \\
\text { Poids final }(\mathrm{kg})\end{array}$ & $\begin{array}{l}27,7 \\
26,4\end{array}$ & $\begin{array}{l}27,4 \\
28,0\end{array}$ & $\begin{array}{l}28,3 \\
35,7\end{array}$ & $\begin{array}{l}27,5 \\
39,0\end{array}$ & $x x$ & ** & $m$ & 1,4 \\
\hline GMQ $(g / j)$ & $-12,9$ & 5,0 & 71,9 & 109,9 & * & $*$ & $*$ & 14,2 \\
\hline Note état initial & 2,9 & 2,9 & 2,8 & 2,9 & & & & \\
\hline Note état final & 2,0 & 2,7 & 3,2 & 3,6 & ns & ** & * & 0,6 \\
\hline
\end{tabular}

1 Ration de base : $\mathrm{PNT}=$ Paille non traitée, $\mathrm{PT}=$ Paille traitée 